\title{
Economic burden of acute pesticide poisoning in South Korea
}

\author{
Yeongchull Choi', Younhee Kim², Yousun Ko', Eun S. Cha', Jaeyoung Kim ${ }^{3}$ and Won J. Lee' \\ 1 Department of Preventive Medicine, College of Medicine, Korea University, Seoul, South Korea \\ 2 Office of Health Service Research, National Evidence-based Healthcare Collaborating Agency, Seoul, South Korea \\ 3 Department of Preventive Medicine, College of Medicine, Keimyung University, Daegu, South Korea
}

\begin{abstract}
овJEctives To investigate the magnitude and characteristics of the economic burden resulting from acute pesticide poisoning (APP) in South Korea.

METHODS The total costs of APP from a societal perspective were estimated by summing the direct medical and non-medical costs together with the indirect costs. Direct medical costs for patients assigned a disease code of pesticide poisoning were extracted from the Korean National Health Insurance Reimbursement Data. Direct non-medical costs were estimated using the average transportation and caregiving costs from the Korea Health Panel Survey. Indirect costs, incurred by pre-mature deaths and work loss, were obtained using 2009 Life Tables for Korea and other relevant literature.

RESULTS In 2009, a total of 11453 patients were treated for APP and 1311 died, corresponding to an incidence of 23.1 per 100000 population and a mortality rate of 2.6 per 100000 population in South Korea. The total costs of APP were estimated at approximately US $\$ 150$ million, $0.3 \%$ of the costs of total diseases. Costs due to pre-mature mortality accounted for $90.6 \%$ of the total costs, whereas the contribution of direct medical costs was relatively small.

CONCLUSION Costs from APP demonstrate a unique characteristic of a large proportion of the indirect costs originating from pre-mature mortality. This finding suggests policy implications for restrictions on lethal pesticides and safe storage to reduce fatality and cost due to APP.
\end{abstract}

keywords agricultural chemicals, cost, policy, regulation, societal burden

\section{Introduction}

Pesticide poisoning is one of the major public health issues worldwide. Although there is a paucity of information on its incidence and mortality, it is estimated that global annual number of self-inflicted deaths from pesticide has reached a quarter million (Gunnell et al. 2007). Acute pesticide poisoning (APP) is one of the leading causes of morbidity and mortality due to poisoning in East and South-East Asian countries (Awang et al. 2003; Li et al. 2009; Chien et al. 2011). Self-ingestion of pesticide is believed to be one of the commonest methods of suicide, especially in Asia (Bertolote et al. 2006).

In South Korea, highly toxic pesticides remain easily accessible on the market, and pesticide-related illnesses and deaths are prevalent. The age-standardised mortality rate for pesticide poisoning was reported as 5.32 per 100000 population between 1996 and 2005 (Lee et al. 2009), using registered deaths data. Recent studies have reported an annual pesticide-related hospitalisation rate of 17.8 per 100000 population (Kim et al. 2012), and a 26.8 per 100000 population annual average rate of emergency department visits due to pesticide poisoning in South Korea (Ko et al. 2012). Deliberate pesticide self-poisoning is among the most preferred means of suicide in South Korea (Kim et al. 2011). Accidental pesticide poisoning, such as when pesticides are misidentified as cooking ingredients or beverages, is a further common form of pesticide poisoning (Shin et al. 2004) and can lead to fatal consequences. However, the economic burden related to pesticide use has not been examined and pesticide poisoning has failed to draw a corresponding level of attention from either the government or society in South Korea.

Previous studies have been undertaken in several countries to quantify the economic burden of the adverse health effects of pesticide use. These studies, however, are only weakly comparable with one another due to their varying scopes, perspectives, types of exposure treated and economic contexts (Table 1). In Zimbabwe, 280 cotton growers were surveyed to examine the direct and indirect costs of the acute health effects of pesticides (Maumbe $\&$ swinton 2003). The costs of pesticide poisoning and pesticide-related illnesses in the US were also calculated based on an estimated number of cases (Pimentel 2005). 
Y. Choi et al. Economic burden of acute pesticide poisoning

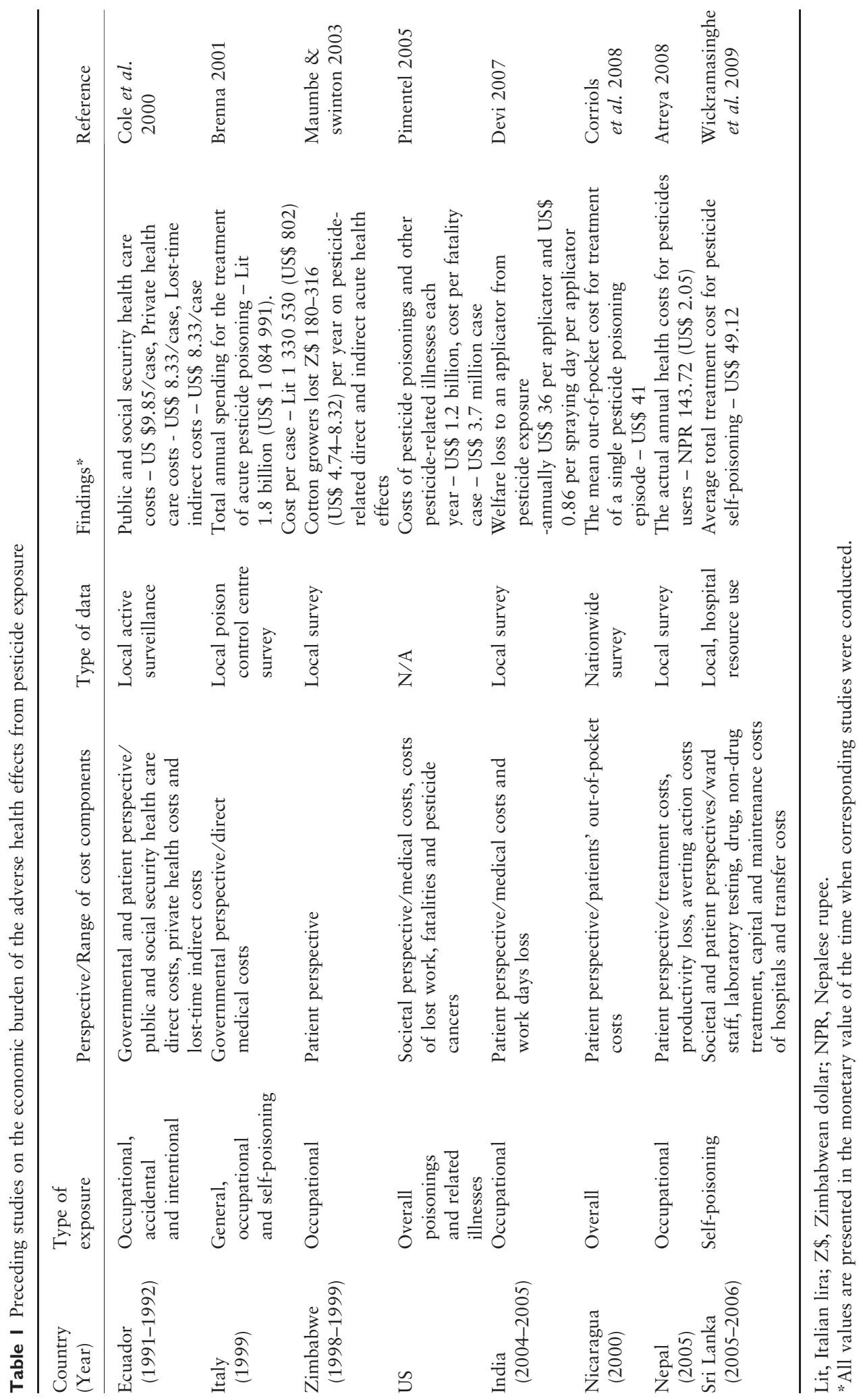


The costs incurred due to pesticide exposure were also examined in a region in Kerala, India (Devi 2007). Using Nicaraguan surveillance data, the average out-of-pocket costs per pesticide poisoning episode were estimated (Corriols et al. 2008). The estimation of annual costs related to occupational pesticide use based on a survey of 291 farm households, including the cost of averting actions, was also conducted in a single area in Nepal (Atreya 2008).

However, most of these studies were confined to limited areas and focused primarily on specific types of exposure, such as occupational and/or intentional pesticide poisoning. In addition, previous studies have mainly depended on self-reported data and included some potential uncertainty and underestimation in their methods. No study that examined the comprehensive cost components beyond purely direct medical costs, and including productivity or work loss has been reported.

This study, therefore, was designed to investigate the overall economic burden incurred by all treated APP incidents in South Korea, regardless of type of exposure (i.e. occupational, accidental and self-inflicted) using national level data. In particular, this study attempted to explore the indirect economic impact of APP by estimating costs of productivity lost due to mortality and morbidity.

\section{Methods}

An APP case was defined as a case of pesticide poisoning reimbursed by National Health Insurance (NHI) or subsidised by National Medical Aid (NMA) and coded from T60.1 to T60.9 according to the Korean Standard Classification of Diseases Version 6 (Statistics Korea 2007), which is equivalent to the International Classification of Diseases-10. Table 2 illustrates the overall cost structure, individual cost components and corresponding sources of parameters used in this study. The costs of APP are largely composed of direct medical costs $\left(C_{m}\right)$, direct non-medical costs $\left(C_{n}\right)$ and indirect costs $\left(C_{i}\right)$. The year 2009 was selected for the estimation since it is the most recent year with the reliable statistics and reference values required for estimation. US dollars were used to present the estimations. According to the average exchange rate for 2009 published by the Bank of Korea, US\$ 1 equalled KRW (Korean Won) 1276.35.

\section{Direct medical costs}

Direct medical costs are composed of NHI reimbursement $\left(C_{m i}\right)$, NHI copayment $\left(C_{m c}\right)$, NHI drug cost $\left(C_{m d}\right)$ and non-NHI copayment $\left(C_{m o}\right)$. National Health Insurance reimbursement cost, NHI copayment and NHI drug cost were derived directly from 2009 NHI reimbursement data provided by the Health Insurance Review and Assessment Service (HIRA) (HIRA 2009). Because all Koreans are enroled in either NHI or NMA (OECD 2009), and NMA subsidy cases were included in the NHI reimbursement data, all APP cases, which received medical treatment in 2009, were considered to be included in the NHI reimbursement data.

Table 2 The cost components of the economic burden of APP

\begin{tabular}{|c|c|c|}
\hline Cost categories & Contents & Parameters (Sources) \\
\hline \multicolumn{3}{|l|}{ Direct medical costs $\left(C_{m}\right)$} \\
\hline \multicolumn{3}{|l|}{ NHI costs } \\
\hline NHI reimbursement $\left(C_{m i}\right)$ & Amount reimbursed by $\mathrm{NHI}$ & National Health Insurance Reimbursement \\
\hline NHI copayment $\left(C_{m c}\right)$ & NHI costs copaid by patients & Data (HIRA 2009) \\
\hline NHI drug cost $\left(C_{m d}\right)$ & NHI costs of purchasing drugs & \\
\hline Non-NHI copayment $\left(C_{m o}\right)$ & $\begin{array}{l}\text { Out-of-pocket payment for NHI } \\
\text { non-covered healthcare services }\end{array}$ & $\begin{array}{l}\text { Non-NHI copayment rate }\left(\mathrm{Po}_{a b}\right) \text { for each } \\
\text { hospital type service (Choi et al. 2010) }\end{array}$ \\
\hline \multicolumn{3}{|l|}{ Direct non-medical costs $\left(C_{n}\right)$} \\
\hline Transportation cost $\left(C_{n t}\right)$ & $\begin{array}{l}\text { Cost of travelling to healthcare } \\
\text { provider }\end{array}$ & $\begin{array}{l}\text { The one-way transportation costs were US\$ } 8.83 \text { for } \\
\text { inpatients and US\$ } 0.52 \text { for outpatients (NHIC 2009) }\end{array}$ \\
\hline Caregiving cost $\left(C_{n c}\right)$ & $\begin{array}{l}\text { Cost of formal and/or informal } \\
\text { caregivers }\end{array}$ & $\begin{array}{l}\text { Mean caring cost per day was US\$ } 37.71 \\
\text { (NHIC 2009) }\end{array}$ \\
\hline \multicolumn{3}{|l|}{ Indirect costs $\left(C_{i}\right)$} \\
\hline $\begin{array}{l}\text { Productivity loss due to } \\
\text { pre-mature death }\left(C_{i d}\right)\end{array}$ & $\begin{array}{l}\text { Productivity loss due to acute } \\
\text { pesticide poisoning deaths }\end{array}$ & $\begin{array}{l}\text { Age- and gender-specific wages (MOEL 2009) } \\
\text { and age- and gender-specific life expectancies } \\
\text { (Statistics Korea 2009a) }\end{array}$ \\
\hline $\begin{array}{l}\text { Work loss due to hospitalisation } \\
\text { and outpatient visits }\left(C_{i m}\right)\end{array}$ & $\begin{array}{l}\text { Short-term or long-term absence } \\
\text { from work due to treatment }\end{array}$ & $\begin{array}{l}\text { Age- and gender-specific wages (MOEL 2009) and Number of } \\
\text { hospitalisation days and outpatient visit days (HIRA 2009) }\end{array}$ \\
\hline
\end{tabular}

APP, acute pesticide poisoning; NHI, National Health Insurance. 
Non-NHI copayment refers to patients' payment not covered by NHI due to limited coverage of Korean NHI system. It was calculated using the non-NHI copayment rates surveyed and provided by the Korean National Health Insurance Corporation (NHIC). Because the specific non-NHI copayment rate of APP was unavailable, each case was assigned a corresponding rate according to its type of provider and service of medical care (e.g. rate for inpatient treatment at general hospitals or outpatient consultation at clinics; Equation 1).

$$
C_{m o}=\sum_{a} \sum_{b} \frac{\left\{\left(C_{m i_{a b}}+C_{m c_{a b}}\right) \times \mathrm{Po}_{a b}\right\}}{\left(1-\mathrm{Po}_{a b}\right)}
$$

Where,

$C_{m i_{a b}}=$ NHI reimbursement cost for each type of provider $(a)$ and medical care $(b)$

$C_{m c_{a b}}=$ NHI copayment for each type of provider $(a)$ and medical care $(b)$

$\mathrm{Po}_{a b}=$ non-NHI copayment rate for each type of provider $(a)$ and medical care $(b)$

\section{Direct non-medical costs}

Direct non-medical costs $\left(C_{n}\right)$ contain two elements: transportation cost $\left(C_{n t}\right)$ and caregiving cost $\left(C_{n c}\right)$. Transportation cost was estimated using the mean values of oneway transportation expenses for inpatients and outpatients. These values (US\$ 8.83 for inpatients and US\$ 0.52 for outpatients) were adopted from the 2009 Korea Health Panel Survey results, as provided by the NHIC and Korea Institute for Health and Social Affairs (KIHASA) (NHIC 2009). It was assumed that APP patients spent the same amount on travelling to their healthcare providers as those surveyed (Equation 2).

The results of the Korea Health Panel Survey 2009 were used once again to estimate caregiving cost. The Korea Health Panel Survey is a nationwide survey on annual medical expenditure and their distribution in South Korea. The mean caregiving cost per day for inpatients with APP was US\$37.70 (NHIC 2009). The proportion of $66.6 \%$ of inpatients being attended by caregivers was adopted from the survey in order to exclude those who had not received any type of caregiving service. It was assumed that informal care services offered by family members or relatives were of equal value to those provided by professional caregivers (Equation 3).

$$
C_{n t}=2\left\{\left(N_{\mathrm{h}} \times T_{\mathrm{h}}\right)+\left(N_{\mathrm{o}} \times T_{\mathrm{o}}\right)\right\}
$$

Where,

$N_{\mathrm{h}}=$ number of hospitalisation cases

$T_{\mathrm{h}}=$ mean one-way transportation cost for inpatients

$N_{\mathrm{o}}=$ number of outpatient visits

$T_{\mathrm{o}}=$ mean one-way transportation cost for outpatients

$$
C_{n c}=D_{\mathrm{h}} \times C_{\mathrm{d}} \times P_{\mathrm{c}}
$$

Where,

$D_{\mathrm{h}}=$ Total hospitalisation days of APP inpatients

$C_{\mathrm{d}}=$ mean caregiving cost per day

$P_{\mathrm{c}}=$ proportion of inpatient cases attended by caregivers

\section{Indirect costs}

Adopting the human capital approach, productivity loss due to pre-mature deaths $\left(C_{i d}\right)$ and work loss due to hospitalisation and outpatient visits $\left(C_{i m}\right)$ comprised indirect costs. In the estimation of productivity loss due to pre-mature deaths, age- and gender-specific average wages and employment rates reported annually by the Korean Ministry of Employment and Labor (MOEL 2009) were used as surrogates for per capita productivity for each gender and age group. Age- and gender-specific numbers of APP deaths and the 2009 Life Tables for South Korea were used to estimate the total years lost due to pre-mature deaths for each gender and age group (Equation 4). Age- and gender-specific lengths of hospital stay and outpatient visit days were extracted from NHI reimbursement data as proxies for work days lost. They were then multiplied by age- and gender-specific average wages to monetize the work losses due to in- and outpatient treatment. It was assumed that each outpatient case lost a half day (Equation 5).

$$
C_{i d}=\sum_{i} \sum_{j} \sum_{\tau} D_{i j} \times \frac{I_{i j}^{t+\tau} \times R_{i j}^{t+\tau}}{\left(1+r_{\mathrm{d}}\right)^{\tau}}
$$

Where

$D_{i j}=$ number of deaths for each age $(i)$ and gender $(j)$

$I_{i j}^{t+\tau}=$ expected income for each age $(i)$ and gender $(j)$ at $t+\tau$

$R_{i j}^{t+\tau}=$ employment rate for each age $(i)$ and gender $(j)$ at $t+\tau$

$t=$ age of death

$\tau=$ years after death (till productive age)

$r_{\mathrm{d}}=$ discount rate

$$
\begin{aligned}
C_{i m}= & \sum_{i} \sum_{j}\left(D I_{i j} \times W_{i j} \times R_{i j}\right) \\
& +\sum_{i} \sum_{j}\left(D O_{i j} \times \frac{1}{2} W_{i j} \times R_{i j}\right)
\end{aligned}
$$


Y. Choi et al. Economic burden of acute pesticide poisoning

Where,

$D I_{i j}=$ total hospitalisation days for each age $(i)$ and gender $(j)$

$W_{i j}=$ wage rate for each age $(i)$ and gender $(j)$

$R_{i j}=$ employment rate for each age $(i)$ and gender $(j)$

$D O_{i j}=$ total outpatient visit days for each age $(i)$ and gender $(j)$

\section{Sensitivity analyses}

For the purpose of sensitivity analyses, various combinations of two parameters were considered. One is the discount rate that refers to the value reduction rate for future income due to time preference, and the other is the productive age range. The three most probable combinations were chosen to yield alternative scenarios. In the base case estimation, the discount rate for future income and productive age range was assumed to be 5\% and 20-69, respectively. In the first and second alternative scenarios, discount rates of $3 \%$ and $7 \%$ were applied respectively, while the productive age range remained unchanged. For the third scenario, an alternative age range of 15-79 was paired with a $5 \%$ discount rate.

\section{Comparative review with other diseases}

Mortality cost per case (i.e. productivity loss per mortality case) of APP was compared with that of other disease groups in order to explore how much was lost by a single APP death. In addition, comparisons of the proportions of cost components between APP and other major disease groups were also performed for the identification of how much share of the overall costs could be attributed to each cost component. Two studies with similar scopes and approaching methods, which dealt with the costs of major disease groups in South Korea (Jung 2010; Lim et al. 2011), were identified for this comparison. Because these studies were based on 2006 or 2007 data, costs were converted into 2009 values by means of the consumer price index. Costs for infectious diseases, cancers, cardiovascular diseases and respiratory diseases were obtained from Jung's study, and cost for injuries from those of Lim et al. 2011, respectively. Although certain parameters were drawn from different sources than those used in this study, they were mutually comparable considering the similarity of the methods used for indirect cost estimation, the study perspective and cost structure.

\section{Results}

In 2009, a total of 11453 patients, including 5732 inpatients and 5721 outpatients, were treated for APP (Table 3). Patients between 20 and 64 years of age accounted for $60.2 \%$. Deaths from APP totalled 1311 in 2009 and patients aged 65 or older accounted for $54.7 \%$

Table 3 Incidence and mortality rates for acute pesticide poisoning by age and gender in South Korea, 2009

\begin{tabular}{|c|c|c|c|c|c|c|}
\hline & \multicolumn{2}{|l|}{ Both sexes } & \multicolumn{2}{|l|}{ Male } & \multicolumn{2}{|l|}{ Female } \\
\hline & $\begin{array}{l}\text { Number of } \\
\text { patients or } \\
\text { deaths }\end{array}$ & $\begin{array}{l}\text { Incidence or } \\
\text { mortality rate } \\
\text { (per } 100000)\end{array}$ & $\begin{array}{l}\text { Number of } \\
\text { patients or } \\
\text { deaths }\end{array}$ & $\begin{array}{l}\text { Incidence or } \\
\text { mortality rate } \\
\text { (per } 100000)\end{array}$ & $\begin{array}{l}\text { Number of } \\
\text { patients or } \\
\text { deaths }\end{array}$ & $\begin{array}{l}\text { Incidence or } \\
\text { mortality rate } \\
\text { (per } 100 \text { 000) }\end{array}$ \\
\hline Total patients & 11453 & 23.1 & 6820 & 27.4 & 4633 & 18.7 \\
\hline \multicolumn{7}{|l|}{ Inpatients } \\
\hline Total & 5732 & 11.5 & 3451 & 13.9 & 2281 & 9.2 \\
\hline 0-19 & 131 & 1.1 & 75 & 1.2 & 56 & 1.0 \\
\hline $20-64$ & 3477 & 10.7 & 2125 & 12.8 & 1352 & 8.4 \\
\hline $65+$ & 2124 & 41.1 & 1251 & 60.0 & 873 & 28.3 \\
\hline Average hospitalisation days & 8.6 days & & 8.7 days & & 8.5 days & \\
\hline \multicolumn{7}{|l|}{ Outpatients } \\
\hline Total & 5721 & 11.5 & 3369 & 13.5 & 2352 & 9.5 \\
\hline $0-19$ & 341 & 2.9 & 183 & 3.0 & 158 & 2.8 \\
\hline $20-64$ & 3372 & 10.3 & 2012 & 12.1 & 1360 & 8.5 \\
\hline $65+$ & 2008 & 38.9 & 1174 & 56.3 & 834 & 27.0 \\
\hline Average number of visits & 1.5 visits & & 1.4 visits & & 1.6 visits & \\
\hline \multicolumn{7}{|l|}{ Mortality cases } \\
\hline Total & 1311 & 2.6 & 844 & 3.4 & 467 & 1.9 \\
\hline $0-19$ & 7 & 0.1 & 5 & 0.1 & 2 & 0.0 \\
\hline $20-64$ & 587 & 1.8 & 396 & 2.4 & 191 & 1.2 \\
\hline $65+$ & 717 & 13.9 & 443 & 21.3 & 274 & 8.9 \\
\hline
\end{tabular}

Data source: National Health Insurance Reimbursement Data 2009. 
of all mortality. The overall incidence and mortality rates of APP were 23.1 per 100000 and 2.6 per 100 000, respectively. Both incidence and mortality rates were higher among men and were highest in the age group of 65 or older. The case fatality rate based on NHI data was $11.4 \%$.

The total costs of APP in 2009 were estimated at approximately US\$ 150 million (Table 4). Of this amount, indirect costs of US\$ 135 million, which mainly originated from pre-mature mortality, accounted for $90.6 \%$ of the total costs of APP, while direct medical costs accounted for $<8.5 \%$. Transportation and caregiving costs were negligible compared with other cost components. The NHI reimbursement for APP of US\$ 7.8 million was $0.05 \%$ of the total NHI reimbursement for all diseases of US\$ 16.6 billion in 2009 (NHIC/HIRA 2010).

In the first and second alternative scenarios, when $3 \%$ and $7 \%$ discount rates for future income were applied without changes in the age range total APP costs changed to US\$ 177 million and US\$ 130 million, respectively. Meanwhile, when the productive age range was extended to $15-79$, total costs increased to US\$157 million. Most changes in the cost resulted from changes in mortality cost, while work loss due to hospitalisation and outpatient visits were not affected greatly, and direct cost components remained constant.

Age-specific costs of APP by cost component are shown in Table 5. Although the age group of 40-49 recorded the highest in terms of total costs, the cost per patient was greatest among those aged 30-39. Direct medical costs per patient were relatively higher among teenagers and young adults (US\$ 1726 for the 10-19 age group, US\$ 1674 for the 20-29 age group). Work loss due to hospitalisations and outpatient visits per patient showed the highest cost in the 30-39 age group, followed by 40-49. Lost productivity per death also peaked among the young adult groups (US\$ 295306 for the 30-39 age group and US\$ 291151 for the 20-29 group), which reflected longer life expectancies and the resulting greater loss of productive years among relatively younger age groups. In general, when judged according to per capita cost, young adult groups were more responsible for costs due to APP.

The mortality cost per APP death was estimated and compared with that of other disease groups (Table 6). In the human capital approach, the mortality cost per death is largely dependent on the mean age of death; as the mean age of death decreases, mortality cost per death increases. The mortality cost per APP death was higher than that of most other disease groups - second only to infectious disease - and twice as much as that of overall diseases. This implicates that younger patients are more affected by fatal APP cases compared with other diseases.

Figure 1 illustrates the comparison of different cost component shares between APP and other disease groups. Whereas the proportions of direct medical costs for other major disease groups, such as infectious diseases, cancers, cardiovascular diseases and respiratory diseases, ranged from $31.8 \%$ to $60.4 \%$, that of APP comprised only $8.5 \%$ of total costs. Instead, the majority of APP costs stem from pre-mature death $(88.6 \%)$. Although injuries was the only group comparable to APP in terms of proportion of indirect costs, its proportion of mortality cost $(61.2 \%)$ was still much smaller than that of APP.

Table 4 Economic burden of APP in South Korea, 2009 (US\$)

\begin{tabular}{|c|c|c|c|c|}
\hline Categories & $\begin{array}{l}\text { Base case (Age } \\
\text { range: } 20-69, \\
\text { Discount rate } 5 \% \text { ) }\end{array}$ & $\begin{array}{l}\text { Alternative } \\
\text { scenario } 1 \\
(20-69,3 \%)\end{array}$ & $\begin{array}{l}\text { Alternative } \\
\text { scenario } 2 \\
(20-69,7 \%)\end{array}$ & $\begin{array}{l}\text { Alternative } \\
\text { scenario } 3 \\
(15-79,5 \%)\end{array}$ \\
\hline Total costs & 149451273 & 177190229 & 129674579 & 157110214 \\
\hline Direct medical costs & 12645318 & 12645318 & 12645318 & 12645318 \\
\hline NHI reimbursement & 7797631 & 7797631 & 7797631 & 7797631 \\
\hline NHI copayment & 2057166 & 2057166 & 2057166 & 2057166 \\
\hline NHI drug cost & 36938 & 36938 & 36938 & 36938 \\
\hline Non-NHI copayment & 2753583 & 2753583 & 2753583 & 2753583 \\
\hline Direct non-medical costs & 1378178 & 1378178 & 1378178 & 1378178 \\
\hline Transportation cost & 127288 & 127288 & 127288 & 127288 \\
\hline Caring cost & 1250890 & 1250890 & 1250890 & 1250890 \\
\hline Indirect costs & 135427777 & 163166733 & 115651083 & 143086718 \\
\hline Productivity loss due to pre-mature deaths & 132410977 & 160149933 & 112634283 & 139735936 \\
\hline $\begin{array}{l}\text { Work loss due to hospitalisations and } \\
\text { outpatient visits }\end{array}$ & 3016800 & 3016800 & 3016800 & 3350782 \\
\hline
\end{tabular}

NHI, National Health Insurance.

Data sources: HIRA 2009; NHIC 2009; MOEL 2009; Statistics Korea 2009 a. 
Y. Choi et al. Economic burden of acute pesticide poisoning

Table 5 Age-specific costs of APP in South Korea, 2009 (US\$)

\begin{tabular}{|c|c|c|c|c|c|c|c|c|}
\hline & \multicolumn{2}{|l|}{ Overall costs } & \multicolumn{2}{|c|}{ Direct medical costs } & \multicolumn{2}{|c|}{$\begin{array}{l}\text { Work loss due to } \\
\text { hospitalisation and } \\
\text { outpatient visits }\end{array}$} & \multicolumn{2}{|c|}{$\begin{array}{l}\text { Productivity loss due } \\
\text { to pre-mature mortality }\end{array}$} \\
\hline & Total & Per patient & Total & Per patient & Total & Per patient & Total & Per deaths \\
\hline Sum & 149451273 & 13049 & 12645318 & 1104 & 3016800 & 263 & 132410977 & 101000 \\
\hline $0-9$ & 82841 & 262 & 69769 & 221 & - & - & - & - \\
\hline $10-19$ & 1828123 & 11719 & 269251 & 1726 & - & - & 1540118 & 220017 \\
\hline $20-29$ & 9533792 & 23775 & 671192 & 1674 & 81175 & 202 & 8734523 & 291151 \\
\hline $30-39$ & 30174474 & 28359 & 1537282 & 1445 & 439827 & 1097 & 28054025 & 295306 \\
\hline $40-49$ & 45644681 & 20607 & 2876462 & 1299 & 1094662 & 1029 & 41388880 & 240633 \\
\hline $50-59$ & 36585133 & 16728 & 2194764 & 1004 & 996102 & 450 & 33138822 & 171704 \\
\hline $60-69$ & 23050031 & 10217 & 2852872 & 1265 & 405034 & 185 & 19554609 & 76685 \\
\hline $70+$ & 2552198 & 893 & 2173726 & 761 & - & - & - & - \\
\hline
\end{tabular}

Data sources: HIRA 2009; NHIC 2009; MOEL 2009; Statistics Korea 2009a.

\begin{tabular}{lrrr}
\hline & $\begin{array}{l}\text { Number of } \\
\text { deaths }\end{array}$ & $\begin{array}{l}\text { Cost due to } \\
\text { pre-mature deaths } \\
\text { (US\$ in 2009 value) }\end{array}$ & $\begin{array}{l}\text { Cost per mortality } \\
\text { case (US\$ in } \\
2009 \text { value)* }\end{array}$ \\
Cause of death (year) & 1311 & 132410977 & 101000 \\
APP (2009) & 5349 & 619357402 & 115789 \\
Infectious diseases (2007) & 68335 & 5393748772 & 78931 \\
Cancers (2007) & 57574 & 2735042304 & 47505 \\
Cardiovascular diseases (2007) & 14864 & 336764890 & 22656 \\
$\begin{array}{l}\text { Respiratory diseases (2007) } \\
\text { Injuries (2006) } \dagger\end{array}$ & 29495 & 19960046055 & 676726 \\
$\begin{array}{l}\text { All diseases except for } \\
\text { injuries (2007) }\end{array}$ & 244874 & 14006733025 & 57200 \\
\hline
\end{tabular}

Table 6 Comparison of mortality cost per death from APP with other disease groups in South Korea

APP, acute pesticide poisoning.

Data source: Statistics Korea 2009b; Jung 2010; Lim et al. 2011.

*Numbers were rounded up to integers.

$\dagger$ Because the cost of injuries was calculated from different data source and methods, direct comparison with other diseases would have some limitations.

\section{Discussion}

This study based on national data estimated total APP costs at US\$ 150 million in 2009, which accounted for $0.30 \%$ of the estimated costs of all diseases in South Korea (Jung 2010). Meanwhile, the NHI reimbursement for APP patients was US\$ 7.8 million, which accounted for only $0.05 \%$ of total 2009 NHI reimbursement for all diseases (NHIC/HIRA 2010), a negligible level compared with other major diseases when viewed from the governmentrun NHI perspectives. When compared with other disease groups, however, the cost of APP includes a unique characteristic in that the majority of the total cost was explained by indirect cost resulting from pre-mature mortality. Although total APP costs make up a small proportion of the costs of all diseases, it is important to understand that significant policy implications can be drawn from the large proportion of pre-mature mortality cost.
The substantial proportion of indirect costs can be mainly attributed to the high case fatality rate of APP in South Korea. Because intentional self-poisoning accounted for $84.8 \%$ of total deaths from pesticide poisoning in South Korea (Lee et al. 2009), the large proportion of mortality cost should be closely linked to suicide. The case fatality rate of $11.4 \%$ in this study is comparable to that of emergency room visit patients of $15.0 \%$ (Ko et al. 2012) and that of hospitalised patients of $19.1 \%$ (Kim et al. 2012), considering that NHI data included ambulatory and/or non-emergency cases as well. This high fatality may result from the possible exclusion of mild cases, which did not receive medical attention because NHI data do not capture such cases. The high proportion of self-poisoning from paraquat and the advanced age of the victims may also partially explain the reason.

The unique cost structure could be a disadvantage for APP as a public health issue. Acute pesticide poisoning is 
Y. Choi et al. Economic burden of acute pesticide poisoning

Figure I The relative contribution of cost components to the total cost of APP and other disease groups in South Korea. ${ }^{1}$ Acute pesticide poisoning; ${ }^{2}$ Cardiovascular diseases. Data sources: Statistics Korea 2009b; Jung 2010; Lim et al. 2011.

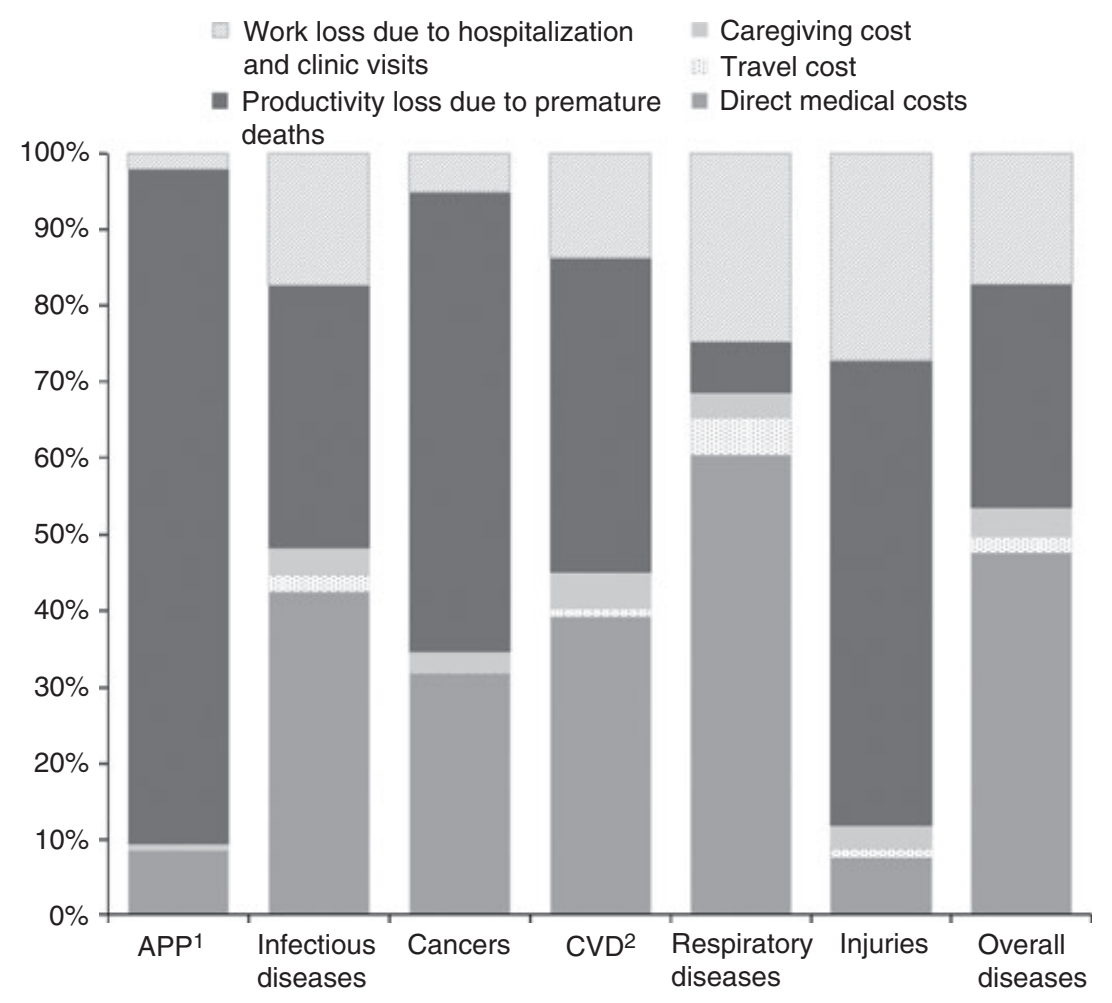

likely to be ignored by the government and hardly becomes an intervention focus because elevated indirect costs do not directly impose any additional burden upon the NHI at the time of incidence. Consequently, APP may fail to attract the attention it deserves from both the government and the public. Thus, the high mortality cost of APP remains a neglected or hidden cost to society.

The results of this study offer the following policy implications. Firstly, given the elevated proportion of costs due to pre-mature deaths and the fact that pesticide ingestion is a common means of suicide, reinforcing regulatory oversight is required for reducing the burden of APP. A number of studies have shown that the wide availability of pesticides is among the most common risk factors for suicide by self-poisoning, and that a ban on the production and distribution of highly lethal pesticides would reduce the number of deaths from pesticide poisoning (Konradsen et al. 2003; Mann et al. 2005; Eddleston et al. 2006; Gunnell et al. 2007). However, a number of highly toxic pesticides, such as paraquat dichloride, which have already been banned in many industrialised countries, remain on the market in South Korea. Even though a ban may not be a thorough intervention strategy for reducing intentional poisonings, based on results in Sri Lanka (Eddleston et al. 2012), it should be considered an urgent and effective technique to reduce the incidence and subsequent cost of APP in the South Korean context of a high suicide rate and inadequacy of current pesticide regulations.

Ease of access to pesticides is particularly problematic if a suicide attempt is impulsive or minimally planned (Chen et al. 2012). Pesticide self-poisoning can be impeded when pesticides are unavailable in a moment of emotional crisis (Gunnell \& Eddleston 2003). Thus, establishing appropriate storage system could also provide an effective strategy for minimising costs due to self-inflicted poisonings, most of which occurred in impulsive attempts.

It is also important to improve accessibility to medical services. A recent nationwide survey showed that the incidence rate of occupational APP was 24.7 per 100 male farmers, and that only $12 \%$ of the cases among South Korean farmers received medical attention (Lee et al. 2012). In addition, according to another national survey, roughly one-quarter of farmer respondents answered that long distance from healthcare facilities was a crucial difficulty facing agricultural healthcare service (as opposed to $4.2 \%$ among urban residents), while $15 \%$ of the farmers pointed to reducing the travel time to medical service providers as the most needed change for improving healthcare conditions (compared to $2.6 \%$ among urban citizen; Statistics Korea 2008). Considering that the majority of death and emergency department visits due to 
pesticide poisoning occurred in rural areas (Lee et al. 2009; Ko et al. 2012) where residents experience a greater deprivation of healthcare services than urban citizens, access to high-quality medical service in agricultural areas should be improved for proper and timely care.

This study is the initial attempt to estimate the economic burden of APP in South Korea based mainly on NHI data. The advantage of using NHI data includes that the estimation was able to incorporate all APP cases reimbursed by NHI or NMA because the entire population is enroled in either programme. This study also included all types of exposure and was based on comprehensive elements of the cost of APP, including direct and indirect medical costs.

National Health Insurance data, as secondary data, have a limitation as well that they lack precise information such as the occupation of individual patients, exposure details and/or the validity of each case that would be needed for detailed analysis. A lack of information on the validity of NHI data for APP is being a potential weakness of our study. However, APP cases may be more accurately reported than other causes of diseases because pesticide poisoning may be more likely to evoke action from family or friends in seeking medical attention. But there could be a degree of under-reporting of occupational pesticide poisoning cases, and this may lead to underestimation of APP incidence and costs.

Another limitation is that APP costs in this study could be underestimated because there may exist untreated or selftreated cases of occupational APP due to impediments to access to healthcare service in agricultural regions. Because such cases were not captured in the NHI data, NHI costs may represent only a portion of the full economic burden of APP. Transportation cost may be another source of underestimation. Because patients in agricultural areas generally are required to travel farther to find hospitals capable of providing appropriate services, especially for severe APP cases, transportation costs for farmers may be higher than estimated in this study. Disability costs were not included in this analysis due to lack of information regarding the proportion of disability after APP and in the appropriate quantification data for estimation of disability cost. However, the inclusion in the analysis of disability costs after poisoning might provide a more precise cost value of APP. Further, the impact of suicide on the community was not included in the estimation, which led to the underestimation of the societal burden of APP.

To better understand the actual characteristics of economic burden of APP and to verify the accuracy of secondary data, efforts need to be given to establishing active surveillance system through which more detailed information on causative pesticides, type of exposure and outcome of treatment could be obtained. Voluntary or mandatory notification programmes from affected persons, hospital staff and poisoning control centres are required to be activated as the core of active surveillance system. Sentinel centres could also provide reliable epidemiological information on the magnitude and causative chemicals of pesticide poisoning. None of these programmes, however, is currently in operation in South Korea. Despite a potential problem of under-reporting (Corriols et al. 2008), an active surveillance system for pesticide-related illnesses could provide policymakers and researchers with a source of appropriate information.

In summary, the total costs of APP in South Korea are relatively small compared with other major diseases. The majority of the costs originated from pre-mature deaths, however, are occluded from the insurer's perspective, which does not incorporate societal burden. Acute pesticide poisoning costs need to be judged from a societal perspective in order to understand their true economic burden and informative share among cost components. Considering only direct costs inevitably leads to underestimation of the cost of APP and may result in inadequate intervention strategies.

\section{Acknowledgements}

This work was supported by the National Research Foundation of Korea grant funded by the Korean government (MEST) (No. 2010-0021742) and by the Cooperative Research Programme for Agriculture, Science and Technology Development (Project No. PJ007455), Rural Development Administration, Republic of Korea.

\section{References}

Atreya K (2008) Health costs from short-term exposure to pesticides in Nepal. Social Science and Medicine 67, 511-519.

Awang R, Rahman AF, Abdullah WZ, Lajis R \& Majid MI (2003) Trends in inquiries on poisoning: a five-year report from the National Poison Centre, Malaysia. Medical Journal of Malaysia 58, 375-379.

Bertolote JM, Fleischmann A, Eddleston M \& Gunnell D (2006) Deaths from pesticide poisoning: a global response. British Journal of Psychiatry 189, 201-203.

Brenna E (2001) Health costs of acute poisoning with pesticides: empirical analysis. Annali dell'Istituto superiore di sanità 37 , 153-157.

Chen YY, Wu KC, Yousuf S \& Yip PS (2012) Suicide in Asia: opportunities and challenges. Epidemiologic Reviews 34, 129-144.

Chien WC, Lin JD, Lai CH, Chung CH \& Hung YC (2011) Trends in poisoning hospitalization and mortality in Taiwan, 1999-2008: a retrospective analysis. BMC Public Health 11, 703. 
Choi Y, Baek S, Lim E, Lee H \& Chang H (2010) Medical expenditure by hospital type. In: NHI Patients Medical Expenditure Survey 2009 (ed. W Chung) Health Insurance Policy Research Institute, Seoul, South Korea, pp. 51-67.

Cole DC, Carpio F \& Leon N (2000) Economic burden of illness from pesticide poisonings in highland Ecuador. Revista panamericana de salud públic 8, 196-201.

Corriols M, Marin J, Berroteran J, Lozano LM, Lundberg I \& Thorn A (2008) The Nicaraguan Pesticide Poisoning Register: constant underreporting. International Journal of Health Services 38, 773-787.

Devi PI (2007) Pesticide Use in the Rice Bowl of Kerala: Health Costs and Policy Options South Asian Network for Development and Environmental Economics (SANDEE), Kathmandu, Nepal, pp 1-40.

Eddleston M, Karunaratne A, Weerakoon M et al. (2006) Choice of poison for intentional self-poisoning in rural Sri Lanka. Clinical Toxicology (Philadelphia) 44, 283-286.

Eddleston M, Adhikari S, Egodage S et al. (2012) Effects of a provincial ban of two toxic oganophosphorus insecticides on pesticide poisoning hospital admissions. Clinical Toxicology (Philadelphia) 50, 202-209.

Gunnell D \& Eddleston M (2003) Suicide by intentional ingestion of pesticides: a continuing tragedy in developing countries. International Journal of Epidemiology 32, 902-909.

Gunnell D, Eddleston M, Phillips MR \& Konradsen F (2007) The global distribution of fatal pesticide self-poisoning: systematic review. BMC Public Health 7, 357.

HIRA (2009) National Health Insurance Reimbursement Data Health Insurance Review and Assessment Service, Seoul, South Korea.

Jung Y (2010) Cost of illness and health-friendly fiscal policy (In Korean). In: Health and Welfare Issue and Focus (ed. Y Kim) Korea Institute for Health and Social Welfare, Seoul, South Korea, pp. 1-8.

Kim SY, Kim MH, Kawachi I \& Cho Y (2011) Comparative epidemiology of suicide in South Korea and Japan: effects of age, gender and suicide methods. Crisis 32, 5-14.

Kim HJ, Cha ES, Ko Y, Kim J, Kim SD \& Lee WJ (2012) Pesticide poisonings in South Korea: findings from the National Hospital Discharge Survey 2004-2006. Human \& Experimental Toxicology. 31, 751-758.

Ko Y, Kim HJ, Cha ES, Kim J \& Lee WJ (2012) Emergency department visits due to pesticide poisoning in South Korea, 2006-2009. Clinical Toxicology (Philadelphia) 50, 114-119.

Konradsen F, Van Der Hoek W, Cole DC et al. (2003) Reducing acute poisoning in developing countries-options for restricting the availability of pesticides. Toxicology 192, 249-261.
Lee WJ, Cha ES, Park ES, Kong KA, Yi JH \& Son M (2009) Deaths from pesticide poisoning in South Korea: trends over 10 years. International Archives of Occupational and Environmental Health 82, 365-371.

Lee WJ, Cha ES, Park J, Ko Y, Kim HJ \& Kim J (2012) Incidence of acute occupational pesticide poisoning among male farmers in South Korea. American Journal of Industrial Medicine 55, 799-807.

Li Y, Sun C, Qiu Z et al. (2009) Clinical toxicology in China: current situation and future development. Clinical Toxicology (Philadelphia) 47, 263-269.

Lim SJ, Chung WJ \& Cho WH (2011) Economic burden of injuries in South Korea. Injury Prevention 17, 291-296.

Mann JJ, Apter A, Bertolote J et al. (2005) Suicide prevention strategies: a systematic review. Journal of the American Medical Association 294, 2064-2074.

Maumbe BM \& swinton SM (2003) Hidden health costs of pesticide use in Zimbabwe's smallholder cotton growers. Social Science and Medicine 57, 1559-1571.

MOEL (2009) Working Conditions Survey 2009. Ministry of Employment and Labor (MOEL), Seoul, South Korea.

NHIC (2009) Korea Health Panel Survey 2009. Korea National Health Insurance Corporation (NHIC), Seoul, South Korea.

NHIC/HIRA (2010) National Health Insurance Statistical Yearbook. National Health Insurance Corporation (NHIC) and Health Insurance Review \& Assessment Service (HIRA), Seoul, South Korea.

OECD (2009) Access to Care. In Health at a Glance 2009. Organisation for Economic Co-operation and Development (OECD), Paris, France, pp. 144-155.

Pimentel D (2005) Environmental and economic costs of the application of pesticides primarily in the United States. Environment, Development and Sustainability 7, 229-252.

Shin SD, Suh GJ, Rhee JE, Sung J \& Kim J (2004) Epidemiologic characteristics of death by poisoning in 1991-2001 in Korea.

Journal of Korean Medical Science 19, 186-194.

Statistics Korea (2007) Korean Standard Classification of Diseases. Statistics Korea, Seoul, South Korea.

Statistics Korea (2008) Farmers, Foresters and Fishermen Welfare Survey. Statistics Korea, Seoul, South Korea.

Statistics Korea (2009a) Life Table 2009. Statistics Korea, Seoul, South Korea.

Statistics Korea (2009b) Cause of Deaths. Statistics Korea, Seoul, South Korea.

Wickramasinghe K, Steele P, Dawson A et al. (2009) Cost to government health-care services of treating acute self-poisonings in a rural district in Sri Lanka. Bulletin of the World Health Organization 87, 180-185.

Corresponding Author Won J. Lee, Department of Preventive Medicine, College of Medicine, Korea University, Anam-dong 5-ga, Seongbuk-gu, Seoul, South Korea. E-mail: leewj@korea.ac.kr 